\title{
METODE PENGINJILAN YESUS DALAM INJIL YOHANES 4:1-42
}

\author{
Harming \\ Sekolah Tinggi Teologi Simpson Ungaran \\ Jl. Agung No. 66, RT. 03/RW.04, Krajan, Kel. Susukan, \\ Kec. Ungaran Timur, Kab. Semarang, Jawa Tengah \\ Email: harming@ sttsimpson.ac.id
}

\begin{abstract}
Harming, Methods of Evangelism Jesus In John 4:1-42. This type of research in this study is a qualitative research. The object of this study is the Gospel of John 4: 1-42. In writing this paper, the author will explain Evangelism approach used by Jesus Christ in the midst of people who have complex problems in the areas of social or cultural as faced by the Samaritan woman in the text of the Gospel of John 4: 1-42. Jesus broke through that gap by providing a new understanding to them that the most important thing is to hear the gospel of salvation. This approach is still relevant for believers who have the burden of evangelism.
\end{abstract}

Keywords: Jesus approaches, Methods, Evangelism.

ABSTRAK: Harming, Metode Penginjilan Yesus Dalam Injil Yohanes 4:1-42. Jenis penelitian dalam penelitian ini adalah penelitian kualitatif. Objek penelitian ini adalah Injil Yohanes 4:1-42. Dalam penulisan makalah ini, penulis akan memaparkan pendekatan Penginjilan yang dipakai oleh Yesus Kristus di tengah-tengah masyarakat yang memiliki permasalahan yang kompleks di bidang sosial, maupun budaya seperti yang dihadapi oleh perempuan Samaria dalam teks Injil Yohanes 4:1-42. Yesus menerobos kesenjangan itu dengan memberikan pemahaman baru bagi mereka bahwa hal yang terpenting ialah mendengar tentang Injil keselamatan. Pendekatan ini juga masih relevan bagi orang-orang percaya yang memiliki beban terhadap penginjilan.

Kata kunci: Pendekatan Yesus, Metode, Penginjilan.

\section{PENDAHULUAN}

Penginjilan merupakan sebuah tanggung jawab semua orang percaya kepada Kristus, para misionaris memberikan beberapa metode dalam melaksanakan penginjilan, dengan tujuan agar Injil yang di sampaikan dapat diterima oleh pendengar. Namun dalam realita pelaksanaannya, sering kali metode yang telah di ajarkan tidak sesuai dengan fakta di lapangan. Menurut penulis hal ini disebabkan adanya perbedaan konteks budaya dan sosial antara teori dengan lapangan.

Dalam artikel ini penulis memaparkan sebuah metode penginjilan yang digunakan oleh Yesus ketika melakukan pelayanan. Hal ini tampak dalam pelayanan Yesus terhadap perempuan Samaria merupakan contoh metode penginjilan yang menggunakan situasi konteks dimana orang yang diinjili berada.

Orang-orang Samaria sebagai penduduk Israel Utara pada tahun 722 SM ditaklukkan oleh bang- sa Asyur di bawah kepemimpinan Sargon. ${ }^{1}$ Mereka dibuang ke tempat lain karena melakukan yang jahat dimata Tuhan (2 Raj. 17:23) dan yang ditinggalkan hanya orang-orang miskin dan orang-orang lemah, kemudian Sargon memasukkan penduduk bangsabangsa lain dari Babel, Kuta, Awa, Hamat, dan Serafim, lalu menyuruh mereka diam di kota Samaria menggantikan orang-orang Israel. ${ }^{2}$ Dengan situasi seperti itu maka terjadilah perkawinan campur antara bangsa-bangsa asing yang datang ke daerah Israel utara dengan bangsa Israel yang masih tinggal, yang kemudian menjadi inti masyarakat baru di daerah tersebut. Mereka yang kawin campur tetap mengadakan

${ }^{1}$ Sargon (Ibrani sargon; LXX Arna; arti namanya 'ilah telah mendirikan kerajaan') Ia memerintah Asyur tahun 722-705 sM. Ia disebut dalam Perjanjian Lama hanya satu kali (Yes 20:1), Lih. Douglas, Ensiklopedi Alkitab Masa Kini Jilid II (Jakarta: Yayasan Komunikasi Bina Kasih/OMF, 2003), 352.

${ }^{2}$ Ola Tulluan, Tafsiran Injil Yohanes 1-5 (Malang: Sekolah Tinggi Teologia, 1993), 59. 
ibadah kepada Yahweh, tetapi juga menyembah kepada berhala. Dalam hal ini di Samaria terjadi sinkretisme agama antara agama Israel dan agama kafir. Namun demikian bangsa Samaria tetap memiliki hubungan dengan bangsa Yahudi. Hubungan antara kedua ras ini (Yahudi dan Samaria) sebelum kejatuhan Yerusalem pada $586 \mathrm{sM}$ tetap masih dipelihara.

Pola keagamaan orang Samaria ada kemiripan dengan umat Yahudi (Yudaisme) dalam hal menyembah satu Tuhan Yang Esa (Yahweh), perayaan hari Sabat, perayaan Paskah.Akan tetapi, ada beberapa hal lain yang membedakan. Pertama, sebagai Kitab Suci; mereka hanya mengakui Taurat Musa yang sedikit sesuai keyakinan mereka. Kitab-kitab para nabi dan kitab-kitab lain di dalam kitab suci Ibrani tidak mereka akui sebagai bagian kitab suci. Kitab Taurat disusun kurang lebih abad ke-1 atau ke-2 SM. Kedua, orang-orang Samaria tidak mengakui Yerusalem sebagai tempat ibadah utama, melainkan bait suci yang di gunung Gerizim. ${ }^{3}$ Dengan situasi keberadaan sosial dan budaya seperti ini, Yesus beserta para pengikut-Nya melakukan perjalanan ke Yerusalem, dengan sengaja Yesus melintasi daerah Samaria ini, tentu dengan suatu tujuan bahwa Yesus ingin memberitakan Injil keselamatan serta merombak paradigma-paradigma orang Yahudi yang berpikir orang di luar mereka adalah orang yang kafir.

\section{METODE}

Jenis penelitian yang digunakan dalam penelitian ini adalah penelitian kualitatif dengan pendekatan studi pustaka yaitu hermeneutik Alkitab terhadap berbagai sumber data atau naskah yang mendukung serta memiliki korelasi dengan judul penelitian. $^{4}$

${ }^{3}$ Gerizim: merupakan gunung suci bagi orang Samaria; karena di atas gunung ini mereka sering datang bersembahyang (Yoh. 4:20) di gunung ini juga mereka datang merayakan Paskah, Pentakosta dan Pondok Daud. J. Doulas, Ensiklopedi Alkitab Masa Kin Jilid I (Jakarta: Yayasan Komunikasi Bina Kasih, 2007), 336.

${ }^{4}$ Stefany John Risna Abrahamsz, "Model Penginjilan dalam Yohanes 4:1-42 dan Implementasinya pada
Objek penelitian ini adalah Injil Yohanes 4:1-42. Sumber utama dalam penelitian ini adalah (1)Alkitab Terjemahan Baru (TB), (2) Alkitab versi Firman Allah Yang Hidup (FAYH), (3) Alkitab versi King James Version (KJV), (4) Interlinear Greek New Testament (IGNT), (5) Biblical Hebrew teks with vowel points (BHvp). Selain itu penelitian juga memanfaatkan aplikasi Sabda (OLB versi Indonesia) Versi 4.30 untuk menjelaskan beberapa hal terkait dengan Injil Yohanes. Sedangkan kutipan ayat-ayat Alkitab dalam beberapa bahasa diambil dari aplikasi SABDA (OLB versi Indonesia) Versi 4.30. Selanjutnya beberapa sumber berupa bahan interpretatif seperti, (1) Buku-buku tafsiran, (2) Alkitab Edisi Studi; (3) Alkitab Penuntun Hidup Berkelimpahan; dan (4) Ensiklopedi Alkitab. Dalam penelitian ini juga merujuk artikel jurnal dan buku-buku berkaitan dengan metode penginjilan.

Gambar 1. Proses penelitian

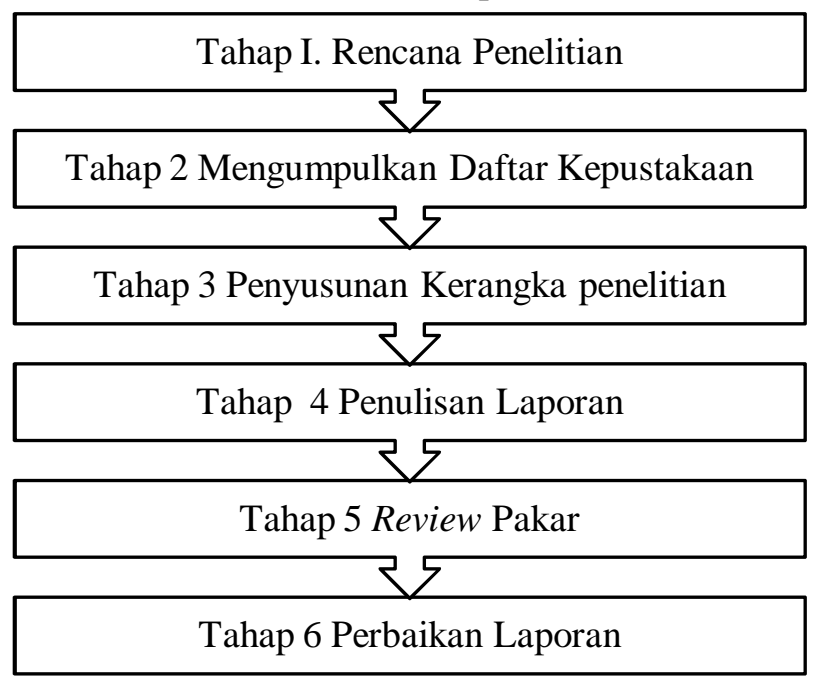

\section{HASIL DAN PEMBAHASAN}

\section{Gambaran Objek Penelitian}

Kota Samaria merupakan kota yang kerap di hindari oleh bangsa Yahudi. Daerah Samaria ini merupakan wilayah perkawinan campur antara orang Yahudi dan bangsa lain, itulah sebabnya wilayah ini

masa Kini," Jurnal Jaffray, Volume 10, Nomor 2 (Oktober 2012): 107. 
dikatakan kafir. Samaria yang merupakan wilayah yang kalau bisa dihindari oleh orang Yahudi. Kini menjadi tempat terjadinya kemenangan rohani: sebuah sumur, seorang wanita, seorang saksi, dimenangkannya sejumlah orang Samaria menjadi orang beriman. Baik Samarianisme maupun Yudaisme perlu dikoreksi oleh Kristus: keduanya perlu diganti dengan kehidupan ciptaan baru. ${ }^{5}$

\section{Konteks Budaya}

Wiryasaputra mengutip definisi budaya dari Matsumoto sebagai berikut: sekumpulan sikap, nilai, keyakinan, serta perilaku yang dimiliki bersama dalam sekelompok orang. Kemudian dikomunikasikan dari generasi kegenerasi berikut melalui bahasa lisan atau tulisan. ${ }^{6}$ Kemudian Purwadi menjelaskan bahwa Kata "Kebudayaan" asal kata "budaya" yang memiliki arti budi daya, buah akal budi, serta adat. Secara historis cenderung melihat byada sebagai warisan yang dialih-turunkan dari generasi satu kegenerasi berikutnya. ${ }^{7}$ Hal tersebut di atas dijelaskan bahwa budaya terkait dengan keseluruhan cara hidup, berpikir dan pandangan hidup sekelompok manusia. Budaya memiliki pengaruh yang sangat besar terhadap perilaku seseorang. Secara kultural Samarenna mengartikan bahwa budaya sebagai kebanggaan ataupun aktualisasi diri suatu suku sehingga berdampak pada sosial masyarakat secara umum masyarakat Indonesia. $^{8}$

Situasi budaya Israel dalam Injil Yohanes 4:1-42 tidak terlepas dari pasal sebelumnya, dimana Yesus bersama-sama murid berada di Galilea mereka menempuh perjalanan melewati Samaria yang mana orang Yahudi (Yesus) tidak boleh bergaul de-

\footnotetext{
${ }^{5}$ Tafsiran Alkitab Wycliffe dalam SABDA (OLB versi Indonesia) Versi 4.30, 6 September 2013.

${ }^{6}$ Totok S. Wiryasaputra, Konseling Antar Budaya Konteks Indonesia (Yogyakarta: Grafika Indah, 2009), 10.

${ }^{7}$ Mudji Sutrisno \& Hendar Putranto, Teori-Teori Kebudayaan (Yogyakarta: Kanisius, 2011), 9.

${ }^{8}$ Desti Samarenna, "Berteologi dalam Konteks Indonesia Modern" Evangelikal: Jurnal Teologi Injili dan Pembinaan Warga Jemaat, Volume 1, Nomor 1 (Januari 2017): 24 .
}

ngan orang Samaria. Karena bagi orang Yahudi. Samaria adalah daerah yang terjadinya budaya kawin campur dengan bangsa lain dan itu bertentangan dengan budaya Yahudi. ${ }^{9}$

\section{Konteks Sosial}

Orang Yahudi tidak bergaul dengan orang Samaria karena bagi orang Yahudi, orang Samaria adalah ras yang tidak murni. Dulu, ketika Asyur menghancurkan kerajaan Israel (Utara), penduduk Samaria dicampur dengan orang-orang dari bangsa jajahan Asyur yang lain. ${ }^{10}$ Berdasarkan keterangan para ahli, Injil Yohanes ditujukan kepada tiga alamat berbeda. ${ }^{11}$ Pertama adalah golongan non-Kristen dengan maksud agar mereka bersedia menerima Yesus sebagai Juruselamat. Kedua adalah golongan Kristen, dengan maksud agar mereka memperoleh penguatan di dalam Kristus atas penderitaan yang mereka alami akibat konflik. Ketiga adalah golongan Kristen yang sudah terpengaruh olehajaran lain sehingga mereka mencampur-adukkan ajaran kekristenan dengan ajaran lain diluar kekristenan. Dalam hal ini, keberadaan orang Samaria ini menjadi suatu yang di anggap kafir oleh orang Yahudi.

\section{Konteks Agama}

Kekristenan muncul sebagai akibat dari kehadiran Yesus Kristus. Kemunculan-Nya dalam sejarah dunia sebagai pergerakan berita utamanya yakni keselamatan kekal yang berajkan dan hidup di dalam pelayanan Yesus dari Nazaret sampai keliling Samaria. ${ }^{12}$ Agama yang dianut oleh sebagian besar

\footnotetext{
${ }^{9}$ Abrahamsz, "Model Penginjilan," 109.

${ }^{10}$ Tafsiran Alkitab Wycliffe, dalam SABDA.

${ }^{11}$ Yohanes Yuniatika \& Yusak Setyawan "Peng-
} hianatan Yudas Iskariot terhadap Yesus dalam Injil Yohanes (Studi Hermeneutik Sosio-Politik Terhadap Narasi Pengkhianatan Yudas Iskariot Terhadap yang Terdapat dalam Injil Yohanes 13:1-35)," Teologia, Volume 6, Nomor 1 (2014): 64.

${ }^{12}$ Decki K. Lolowang "Yesus Sebagai Anak Allah dalam Injil Yohanes" Jurnal Pendidikan Tinggi, Volume 20, Nomor, 23 (2015): 1. 
penduduk Samaria ialah agama Yudaisme akibatnya terjadi kawin campur dan sinkretisme agama.

\section{Model Pendekatan Yesus Kepada Perempuan Samaria}

Perjalanan Misi Yesus, tidak berfokus dikalangan orang Israel atau bangsa Yahudi. Yesus melakukan pelayanan multikultural kepada semua orang. Salah satunya pelayanan Yesus kepada perempuan Samaria. Komunikasi Tuhan Yesus dengan perempuan Samaria merupakan percakapan yang tidak lazim terjadi dalam kebudayaan Israel. ${ }^{13}$

\section{Mencari Orang Yang Membutuhkan}

Yesus melintasi daerah Samaria, karena orang Yahudi biasanya tidak pernah melintasi daerah tersebut. Orang Yahudi bertindak seperti itu, disebabkan adanya permusuhan yang terjadi di antara mereka belum terselesaikan. Yesus justru melewati tempat yang tidak biasa dilewati oleh orang Yahudi, karena ada orang yang ingin Ia selamatkan meskipun hanya satu jiwa. Ellis mengatakan "Yesus benar-benar memahami kelakuan dan kehidupan manusia...." 14 Tenney berpendapat "Ia harus melintasi daerah Samaria", kata "harus" lebih menyiratkan keharusan logis yang menyatakan Kristus memang sengaja lewat dari tempat yang tidak biasanya, karena dorongan Ilahi yang ingin mencari domba Samaria." 15 Jadi dapat disimpulkan bahwa inisiatif yang dilakukan Yesus dengan sengaja melintasi daerah Samaria untuk pergi mencari orang yang membutuhkan-Nya.

Perempuan Samaria yang bertemu dengan Yesus, bukanlah orang yang terpandang di daerah tempat ia berada, Selanjutnya, Tenney menjelaskan bahwa wanita ini adalah kebalikan dari Nikodemus, seorang yang sering melakukan dosa, tidak terpela-

\footnotetext{
${ }^{13}$ Hengki Wijaya, "Kajian Teologis Tentang Penyembahan Berdasarkan Injil Yohanes 4:24" Jurnal Jaffray, Volume 13, Nomor 1 (2015), 79.

${ }^{14}$ D.W. Ellis, Metode Penginjilan (Jakarta: Yayasan Komunikasi Bina Kasih, 1999), 163.

${ }^{15}$ Merril C. Tenney, Injil Iman (Malang: Gandum Mas, 2003), 97.
}

jar, seorang miskin dan hampir terbuang dari dari masyarakat. ${ }^{16}$ Perempuan ini menghindari masyarakat umum sehingga ketika hendak menimba air di sumur ia pergi pada siang hari, karena pada saat itulah situasi sumur sepi. Demikian juga Hagelberg menjelaskan bahwa "Tidak biasa orang pergi ke sumur untuk menimba air pada jam dua belas siang hari". ${ }^{17}$ Hal di atas disimpulkan bahwa wanita ini sengaja menghindari orang lain karena ia merasa tertolak dan merasa terhina, terbukti dari caranya yang datang sendirian ke sumur itu.

Setiap orang pasti memiliki kebutuhan baik secara sosial, persahabatan dan ekonomi, seperti yang dialami oleh perempuan Samaria ini. Ia menghindar dari orang lain, merasa tertolak, terhina dan itu terbukti dari caranya yang datang mengambil air disiang hari, dan kebiasaan ini tidak sesuai dengan yang dilakukan oleh perempuan lain yang sekota dengannya. Baik pada zaman itu maupun saat ini sesungguhnya ada banyak orang mengalami hal yang sama seperti perempuan Samaria ini. Untuk itu sebagai seorang pemberita Injil perlu mencari tahu tentang informasi kebutuhan terkait dengan sosial, persahabatan dan ekonomi dan lain sebagainya, supaya melalui hal itu Injil dengan mudah diberitakan kepada mereka yang belum percaya secara khusus orangorang yang membutuhkan keselamatan. Gereja harus jeli melihat kesempatan ini untuk menjadikannya sebuah peluang yang baik dalam memberitakan Injil.

\section{Membangun Persahabatan}

Ketika Yesus di daerah Samaria dan memulai percakapan dengan seorang perempuan Samaria, dengan tujuan ingin membangun persahabatan dengan orang-orang yang tidak dikenal sebelumnya. ${ }^{18}$ Persahabatan yang dibangun Yesus dimulai dengan sikap yang rendah hati yaitu meminta tolong kepada

\footnotetext{
${ }^{16}$ Ibid.

${ }^{17}$ Dave Hagelberg, Tafsiran Injil Yohanes Pasal 1-5 Dari Bahasa Yunani (Yogyakarta: Andi, 1990), 157.

${ }^{18}$ Makmur Halim, Model-model Penginjilan Yesus Suatu Penerapan Masa Kini, (Malang: Gandum Mas, 2003), 72.
} 
perempuan itu. Tenney berpendapat kata "Berilah Aku minum" yaitu permintaan yang Yesus ajukan itu tidak mungkin ditolak oleh perempuan Samaria ini, karena Ia meminta atas dasar kebaikannya. ${ }^{19}$ Yesus tidak datang seperti seorang yang mengajar atau mendikte apa yang ingin disampaikan, tetapi menempatkan diri-Nya di bawah sehingga wanita ini menjadi heran, karena biasanya sorang Yahudi tidak ingin bergaul dengan orang Samaria dan justru sebaliknya membenci mereka. Kristus mengetahui tentang hal itu, oleh karena itu Ia menempatkan diri sebagai orang yang membutuhkan pertolongan, supaya perempuan Samaria itu tidak merasa terancam atau tertolak, karena Ia adalah seorang Yahudi dan telah diketahui bahwa tidak biasa seorang Yahudi meminta minum kepada seorang Samaria. Yesus melakukan hal yang demikian karena ingin menunjukan sikap berbeda yaitu datang sebagai pembawa damai.

Jadi model persahabatan yang dibangun oleh Yesus ketika menginjili perempuan Samaria ini perlu dicontoh. Ketika membangun persahabatan dengan orang yang belum percaya Injil pun dapat diberitakan dengan baik. Makmur Halim mengatakan:

Di dalam persahabatan ini kita akan menemukan kesempatan-kesempatan untuk memberitakan Injil, sebab melalui persahabatan bisa menemukan adanya kebutuhan khusus dari sahabat atas keterbukaan bersama, ada jalur dalam pembicaraan untuk pemberitaan Injil. ${ }^{20}$

Dari penjelasan Halim di atas, penulis menyimpulkan bahwa sebelum Yesus menginjili perempuan Samaria ini, Ia terlebih dahulu membangun persahabatan. Melalui persahabatan adanya suatu sikap yang saling terbuka, sehingga perempuan Samaria semakin heran dan ingin mengetahui lebih banyak lagi tentang apa yang Yesus ingin katakan kepadanya.

\section{Melibatkan Orang Lain}

Pada waktu Yesus menawarkan kasih karunia Allah kepada seorang perempuan Samaria terle-

\footnotetext{
${ }^{19}$ Tenney, Injil Iman, 91.

${ }^{20}$ Halim, Model-model Penginjilan, 17.
}

bih dahulu Ia menyuruh memanggil suaminya. Susanto menerjemahkan sebagai berikut: "Pergilah, panggil suamimu, lalu kembalilah ke sini" kata Yesus. "Saya tidak punya suami" jawab wanita itu."21 Disini jelas bahwa Yesus tidak memberitakan kasih karunia Allah hanya kepada perempuan itu saja, tetapi juga melibatkan sanak keluarganya terutama orang yang paling berpengaruh yaitu suaminya. Menurut adat orang Yahudi dan Samaria, seorang suami memiliki peran penting, baik dalam kehidupan berkeluarga demikian juga di masyarakat. Sedangkan wanita dianggap sebagai penolong dan pendamping dan urutan dalam tatanan keluarga adalah nomor dua. Jadi Yesus melibatkan suaminya untuk ikut mendengarkan kabar baik itu, supaya pengambilan keputusan dalam keluarga memahami apa yang Yesus hendak beritakan, dan tentunya juga supaya kelak tidak menghambat, bahkan mendukung perubahan kepercayaan iman yang akan terjadi di dalam keluarga besarnya, demikian juga dengan orang yang diinjili.

\section{Meluruskan Pemahaman Yang Keliru}

Kehadiran Yesus di Samaria sangat jelas yaitu ingin merubah pemahaman seorang perempuan Samaria yang masih keliru dalam menilai sebuah kehidupan, terutama dalam memahami tentang menyembah kepada Allah masih tidak jelas. Maka dari itu Yesus mau merekonstruksi paradigma berpikir perempuan tersebut, karena dari pemahaman yang keliru tentang penyembahan kepada Allah menyebabkan cara hidup yang dijalaninya juga salah, jadi penting bagi Yesus untuk meluruskan kekeliruan yang terjadi pada perempuan itu.

\section{Rekonstruksi Ulang Pemahaman Kepercayaan}

Ketika Yesus bertemu dengan perempuan Samaria itu, Dia tidak langsung mengubah paradigma kepercayaannya yang keliru tentang menyembah Allah. Tenney mengatakan tentang pemahman pe-

${ }^{21}$ Hasan Sutanto, Perjanjian Baru Interlinear Yunani-Indonesia dan Konkordansi Perjanjian Baru, (Jakarta: Lembaga Alkitab Indonesia, 2006), 495. 
rempuan yang keliru itu sebagai berikut: "nenek moyang kami menyembah di atas gunung ini, tetapi kamu katakan Yerusalemlah tempat orang menyembah."22 Tenney dengan jelas mengatakan bahwa paradigma kepercayaanya orang Samaria dan orang Yahudi yang keliru sudah merupakan konsep pemahaman dari turun-temurun. Kemudian Yesus mengarah langsung kepada rasa kepercayaannya, dengan cara meluruskan pemahaman yang keliru tersebut. Seperti yang dikatakan oleh Tenney lagi yaitu: Jika engkau sungguh ingin untuk mengetahui kebenaran tentang penyembahan, engkau tidak akan menemukannya dalam garis leluhur kita, tetapi dalam relasi antara hatimu sendiri dengan Allah. Engkau mesti berhubungan dengan Dia melalui Roh-Nya, dan atas dasar kebenaran. ${ }^{23}$

Yesus memulai dengan kalimat yang luar biasa "Mengenal Allah yang benar adalah mengenal Dia dalam roh dan kebenaran." ${ }^{24}$ Artinya, Allah itu roh, bukan fisik (benda). Jadi tidak perlu ke gunung mencari Allah, sebab Allah itu Roh, tidak mungkin manusia dapat menjamah atau membuat-Nya menjadi satu wujud yang kemudian di sembah. Kebenaran adalah Allah, firman hidup itu, firman yang membenarkan. Maka kebenaran, yaitu firman, berhubungan dengan Dia. Memahami Dia, memahami kebenaran-Nya. ${ }^{25}$ Penjelasan ini mengarah pada bagaimana Yesus sedang merekonstruksi pemahaman perempuan itu.

\section{Memulihkan Cara Hidup Yang Salah}

Pertemuan Yesus dengan perempuan Samaria itu, selain meluruskan pemahaman yang keliru Ia juga memulihkan cara hidupnya yang salah. Perempuan ini sesungguhnya tidak senang dalam keberadaannya sendiri itulah sebabnya ia seringkali menghindar dan lebih senang menyendiri.

\footnotetext{
${ }^{22}$ Tenney, Injil Iman, 92.

${ }^{23}$ Ibid, 93.

${ }^{24} \mathrm{Ibid}$.

${ }^{25}$ Ibid.
}

Di dalam melaksanakan penginjilan, sangatlah diperlukan suatu pemahaman yang searah dari orang yang diberitakan Injil, yaitu dengan pemahaman penginjil yang alkitabiah. Dengan demikian, maka diperlukan suatu perubahan pemahaman, karena pemahaman yang salah akan berpengaruh pada cara atau praktik hidup seseorang. Dengan demikian cara hidup yang salah, dikarenakan oleh pemahaman yang keliru.

Cara Yesus mengkomunikasikan cara hidup yang salah kepada perempuan tersebut dengan mengingatkannya akan pengalaman yang pernah ia lakukan sebelumnya. Selain itu, Yesus juga merekonstruksikan cara pandangnya terhadap peribadatan kepada Allah. Dengan cara seperti itu, perempuan Samaria menyadari bahwa ia sedang berkomunikasi dengan Sang Mesias yang di nanti-nantikan oleh orang Israel. Sehingga ia dengan penuh keberanian menyampaikan berita tersebut kepada orang banyak.

\section{Memberitakan Yesus Sebagai Mesias}

Pada waktu Ia menyatakan diri-Nya dan meluruskan pandangannya yang keliru dari kehidupan wanita itu. Yesus tidak langsung menanamkan konsep orang Yahudi mengatakan Mesias akan datang sebagai raja, tetapi Yesus perlahan-lahan menyampaikan sesuai dengan konsep dan pemahaman perempuan itu tentang "Mesias" seperti jawaban wanita itu kepada-Nya: "Aku tahu, bahwa Mesias akan datang, yang disebut juga Kristus; apabila Ia datang, Ia akan memberitakan segala sesuatu kepada kami" (band. ayat 25). Tenney mengatakan:

...Kata-kata ini sekaligus merupakan pengakuan akan ketidak tahuan dan pengharapan wanita sedang menunggu terang dan walau pun ternoda ia bergantung kepada janji Allah dari purbakala bahwa Pelepas akan datang dan membuang kegelapan dari matanya. ${ }^{26}$

Dalam memberitaan Injil dibutuhkan suatu tujuan jelas. Inti berita yang ingin disampaikan adalah mengenai pribadi Krisus sebagai jalan menuju

\footnotetext{
${ }^{26}$ Ibid, 92.
} 
keselamatan. Sebab Dialah jalan satu-satunya yang dapat menjamin keselamatan setiap orang yang percaya kepada-Nya agar memperoleh hidup kekal.

\section{KESIMPULAN}

Hasil penelitian yang penulis lakukan terkait dengan Metode Penginjilan Yesus dalam Injil Yohanes 4:1-42, ada beberapa kesimpulan yaitu: Perta$m a$, perjalanan Yesus melintasi Samaria ialah ingin mencari orang yang membutuhkan keselamatan, dimana orang Samaria merupakan suku yang tidak baik menurut orang Israel. Kedua, komunikasi Yesus dengan perempuan Samaria melalui persahabatan yang dibangun ketika percakapan mereka di tepi sumur. Ketiga, selain membangun persahabatan, juga melibatkan orang yang berpengaruh dalam lingkungan tersebut. Keempat, dalam kebudayaan Samaria dan orang Israel, terdapat perbedaan kebudayaan yang mengakibatkan pemahaman-pemahaman yang keliru dalam mengerti kebenaran tentang Mesias. Dalam pemahaman tersebut, Yesus merekonstruksi ulang pemahaman yang keliru dari perempuan Samaria. Sebelum bertemu dengan Yesus, paradigma perempuan tersebut tentang Konsep keselamatan bahwa Mesias yang dinantikan oleh orang Israel akan menyampaikan segala sesuatu kepada mereka, demikian juga konsep penyembahan kepada Allah di-

\section{DAFTAR RUJUKAN}

Abrahamsz, Stefany John Risna. Model Penginjilan dalam Yohanes 4:1-42 dan Implementasinta pada masa Kini," Jurnal Jaffray, Volume10, Nomor 2 (2 Oktober 2012)

Doulas, J. Ensiklopedi Alkitab Masa Kin Jilid I. Jakarta: Yayasan Komunikasi Bina Kasih, 2007.

Ellis, D.W. Metode Penginjilan. Jakarta: Yayasan Komunikasi Bina Kasih 1999.

Ensiklopedi Alkitab Masa Kini Jilid II. Jakarta: Yayasan Komunikasi Bina Kasih/OMF, 2003.

Hagelberg, Dave. Tafsiran Injil Yohanes Pasal 1-5 Dari Bahasa Yunani. Yogyakarta: Andi, 1990. jelaskan yaitu orang Yahudi menyembah Allah di Yerusalem sedangkan orang Samaria menyembah Allah di Gunung Gerizim. Dalam percakapan tersebut, perempuan Samaria menyampaikan argumenttasinya tentang konsep pemahamannya akan keselamatan didasarkan pada kebiasaan dan budaya orang Israel pada umumnya.

Dari penjelasan perempuan tersebut, Yesus memberikan sebuah pemahaman yang benar tentang Mesias bahwa untuk menyembah Allah bukan persoalan lokasi melainkan berkaitan dengan ketulusan hati karena Allah adalah Roh maka manusia haruslah menyembah-Nya dalam Roh dan kebenaran. Selain itu Yesus juga dalam kesempatan itu sekaligus memulihkan cara hidup yang salah. Terakhir Yesus memberitakan diri-Nya sebagai Mesias yang dinantikan oleh orang Israel.

Metode penginjilan yang digunakan oleh Yesus dalam konteks kepada perempuan Samaria ini menggunakan pendekatan lintas budaya atau multicultural yaitu melalui konteks budaya perempuan tersebut. Dalam pendekatan ini Yesus melihat pemahaman perempuan Samaria tentang keselamatan ini dari perspektif budaya orang Samaria. Kemudian dari pemahaman tersebut Yesus memasukkan berita keselamatan di dalam Injil.

Halim, Makmur. Model-model Penginjilan Yesus Suatu Penerapan Masa Kini. Malang: Gandum Mas, 2003.

Lolowang Decki K."Yesus Sebagai Anak Allah dalam Injil Yohanes," Jurnal Pendidikan Tinggi, Volume 20, Nomor, 23 (2015)

Samarenna, Desti. "Berteologi dalam Konteks Indonesia Modern" Evangelikal: Jurnal Teologi Injili Dan Pembinaan Warga Jemaat, Volume 1, Nomor 1, Januari 2017.

Sutanto, Hasan. Perjanjian Baru Interlinear YunaniIndonesia dan Konkordansi Perjanjian Baru. Jakarta: Lembaga Alkitab Indonesia, 2006. 
Sutrisno, Mudji \& Hendar Putranto, Teori-Teori Kebudayaan. Yogyakarta: Kanisius, 2011.

Tafsiran Alkitab Wycliffe dalam SABDA (YLSA) (OLB versi Indonesia) Versi 4.30, 6 September 2013.

Tenney, Merril C. Injil Iman. Malang: Gandum Mas 2003.

Tulluan, Ola. Tafsiran Injil Yohanes 1-5. Malang: Sekolah Tinggi Teologia, 1993.

Wijaya, Hengki. "Kajian Teologis Tentang Penyembahan Berdasarkan Injil Yohanes 4:24" Jurnal Jaffray, Volume 13, Nomor 1 (2015).
Wiryasaputra, Totok. Konseling Antar Budaya Konteks Indonesia. Yogyakarta: Grafika Indah, 2009.

Yuniatika, Yohanes \& Yusak Setyawan. "Penghianatan Yudas Iskariot terhadap Yesus dalam Injil Yohanes (Studi Hermeneutik Sosio-Politik Terhadap Narasi Pengkhianatan Yudas Iskariot Terhadap yang Terdapat dalam Injil Yohanes 13:1-35)" Teologia, Volume 6, Nomor 1 (2014). 